\title{
Classical radical hysterectomy and nerve-sparing radical hysterectomy in the treatment of cervical cancer
}

\author{
Marcin Makowski, Marek Nowak, Marian Szpakowski, Jacek Władziński, Anna Serwach-Nowińska, \\ Łukasz Janas, Jacek R. Wilczyński
}

Department of Gynecology and Gynecologic Oncology, Polish Mother's Memorial Hospital - Research Institute in Łódź, Łódź, Poland

\begin{abstract}
Aim of the study: To compare Piver III radical hysterectomy (RH) with nerve-sparing radical hysterectomy (NSRH) for cervical cancer patients in terms of postoperative physiology of pelvic autonomic nerves and perioperative complications.

Material and methods: Seventy-three consecutive patients with invasive cervical cancer underwent RH (53 cases) or NSRH (20 cases) from 2001 to 2012 at the Department of Gynecology and Gynecologic Oncology of Polish Mother's Memorial Hospital - Research Institute in Łódź.

Results: Compared with patients treated with RH, patients who underwent NSRH presented no significant difference in terms of operative time (146 vs. 143 minutes, $p>0.05$ ), blood loss and hospital stay (9.2 vs. 7.5 days, $p>0.05$ ). A positive surgical margin was found in 6 cases of $\mathrm{RH}$. No serious surgical complications were found in the NSRH group, while there were 4 cases in the RH group.

Conclusions: Nerve-sparing radical hysterectomy is safe and feasible surgical management for cervical cancer patients, which should improve the physiology of the pelvic autonomic nerve system postoperatively. The technique is relatively new and its oncologic efficiency has not been fully established yet, moreover it requires sophisticated anatomical knowledge and high operative skills.
\end{abstract}

Key words: cervical cancer, surgical treatment, nerve-sparing radical hysterectomy, classical radical hysterectomy, perioperative outcome.

\section{Introduction}

Cervical cancer is a very important diagnostic and therapeutic problem in Poland. Each year, such diagnosis is given to almost 3200 women and almost 1800 women die of cervical cancer. The mortality rates in our country are one of the highest in Europe. At the end of the 1990s, the standardized mortality rate in Poland was almost twice as high as the average rate in Europe. After ten years, in 2008, the mortality rate decreased to 5.8/100 000 but was still higher than the average rate in Europe (3.9/100 000). The $25-59$ age group makes up $70 \%$ of all women threatened with cervical cancer $[1,2]$. The Polish Health Programme for 2006-2015 assumes limitation of the number of deaths of cervical cancer to 500 a year in 2015. The classical radical hysterectomy is the primary treatment in cases of cervical cancer in the stage of clinical advancement IA2-IIA by FIGO. Patients after classical radical hysterectomy develop a wide spectrum of undesired symptoms, which are connected with the damage of autonomic innervation of pelvic organs, among which urinary disorders are dominant. One should list: inability of spontaneous urination, urea retention, decreased stream strength, urinary urgency, interrupted urination, the feeling of incomplete bladder emptying after micturition, urinary incontinence, nocturia [3]. The improvement of the techniques of surgical treatment of cervical cancer should limit early and late complications connected with the surgery, without worsening the radicalness of the procedure. Within the last 15 years, an essential progress in recognition and understanding of anatomy of the autonomic nervous system within the pelvis was observed [4]. The concept of preserving vegetative nerves during the radical hysterectomy became a standard in many centers. The technique which saves vegetative innervation and individual adjustment of the surgical procedure in comparison to the standard radical hysterectomy lead to improvement of the quality of life of patients after radical procedures. The basic assumption of classical radical hysterectomy is excision of the uterus with the vaginal cuff, parametria and pelvic lymphatic nodes and potentially para-aortic nodes. Full oncological radicality is obtained at the expense of the patient's fertility and complications related to the excision of a part of the lymphatic system and vegetative innervation [5]. However, there are surgical techniques aimed to obtain the surgical radicalness with reference to cervical cancer with preserving fertility (radical trachelectomy), saving the lymphatic apparatus 
(sentinel lymph node technique), as well as saving the vegetative innervation (nerve-sparing technique). The technique of radical hysterectomy which saves vegetative innervation developed in the second half of the $20^{\text {th }}$ century, at first in Japan and then also in Europe and North America. In Japan, there were two schools which developed the nerve-sparing technique. The Tokyo school was represented by Kobayashi, who in 1961 described the modified radical hysterectomy with preparation and saving of structures of the vegetative system. Another Japanese centre was the so-called school from Kyoto in which the nerve-sparing technique was developed and propagated also beyond Japan. In Europe, the first surgeries of that type were carried out in Germany and Holland. The first nerve-sparing surgeries in Poland were performed in the $21^{\text {st }}$ century $[3,6-9]$. In the case of classical radical hysterectomy, only urinary bladder and ureters were made visible, prepared and saved. The application of the nervesparing technique requires knowledge of the anatomy of the most important structures of the vegetative nervous system, that is, hypogastric nerve, lower pelvic splanchnic nerve and its cervical and bladder branches. While gaining access to the aforementioned structures, it is also necessary to know the vascular system of basic and vesicouterine ligaments. Damaging the nervous structures of the small pelvis sympathetic system may lead to a series of complications regarding the urinary bladder (relaxation of detrusor muscle, relaxation of sphincter muscle of urethra), rectum and anus (defecation restraining, stimulation of the anus sphincter muscle) [10-14]. In the existing literature regarding the radical hysterectomy which saves vegetative innervation, special attention is paid to occurrence of early urological complications and sexual disorders. Attention is also paid to a longer period of surgical personnel training, what results from the necessity to get to know the small pelvis anatomy more thoroughly as well as learn new surgical techniques. Unfortunately, due to a relatively short observation period there is still no full evaluation of oncological efficiency [15].

The purpose of the work is to present our experience in proceeding with classical radical hysterectomy with the use of the nerve-sparing technique.

\section{Material and methods}

Analysis of data of 73 patients operated at the Department of Gynecology and Gynecologic Oncology of Polish Mother's Memorial Hospital Research Institute in tódź (till 2011 - Department of Gynecological Surgery) in 2001-2012 due to cervical cancer with abdominal radical hysterectomy was done.

Starting from 2010, the nerve-sparing method (which saves the vegetative innervation) was applied at the department to radical hysterectomy. It was carried out based on the surgical technique description presented below. Surgery starts with opening the retroperi- toneal space by means of cutting the round ligaments and infundibulo-pelvic ligaments as well as peritoneum incision. It allows identifying the ureters' course. The next stage is dissection of pelvic lymph nodes. After making the lateral umbilical ligament visible, the perivesical space is bluntly opened, the loose connective tissue which fills the space is harvested and so the obturator nerve and vessels are visible. Similarly, the pararectal space is bluntly opened and on the medial lamina of the broad ligament, $2 \mathrm{~cm}$ below the ureter the lower hypogastric nerve is visible. Typically, as in radical classical hysterectomy of Piver class III, the uterine artery is ligated and incised by its origin from the internal iliac artery [16]. The next stage characteristic of the radical hysterectomy which spares vegetative innervation is separate harvesting, ligation and incision of the superficial uterine vein and deep uterine vein. This stage allows getting access to the nervous part of the cervical ligament of uterus, that is pelvic splanchnic nerve and inferior hypogastric plexus. Then, the front lamina of vesicouterine ligament is released by thorough harvesting, ligation and incision of cervical and vesical vessels. At the moment there is only the release of posterior lamina of vesicouterine ligament left. Having the pelvic splanchnic nerve and inferior hypogastric plexus harvested, after opening the space between uterus and rectum, we incise the uterosacral ligaments and rectovaginal ligaments sparing the nerve structures. Then, the structures due to incision of uterine branches may be put to the side. This is how the vagina's surrounding is made visible, stung and then the uterus with the vaginal cuff is excised. This type of surgery was applied to 20 patients and remaining 53 underwent classical Piver class II and III radical hysterectomy.

The analysis of histopathological examination results was carried out and the evaluation of clinical advancement level based on FIGO classification from 2009 was made. The number of lymphatic nodes removed, presence of metastases in the collected lymphatic nodes, infiltration within the surgical incision line and presence of embolisms with cancerous cells in vessels were analyzed. The course of the procedure, mid-surgical complications, early post-surgical complications were analyzed. Patients' age as well as hospital stay, blood loss (expressed by hemoglobin decrease after the surgery) and also the necessity of red blood cells concentrate transfusion were considered. Statistical analysis was carried out with the use of chi-square test, $t$-student test, Cochran-Cox test and median test with a significance level of $p<0.05$.

\section{Results}

Classical radical hysterectomy was carried out in 53 patients with histopathologically confirmed cervical cancer. 20 patients underwent radical hysterectomy 
with vegetative innervation sparing. 53 patients operated in a classical manner included 19 diagnosed with clinical stage IA2 by FIGO; 22 patients - stage IB1, 4 patients - IB2 and 8 patients - IIA1. In the group of patients operated with the use of the nerve-sparing technique, IA2 stage was noted in 4 patients, IB1 in 12 patients, IB2 in 3 patients and IIA1 in 1 patient (Table I). The distribution of cervical cancer progression as well as the age of patients did not significantly differ in the groups compared (Table I).

When analyzing the cancer grading in the group of patients after classical surgery, the following was stated: G1 in 15 patients, G2 in 32 patients and G3 in 7 patients. In patients after nerve-sparing surgery, 6 cases were $\mathrm{G} 1$ grade, 11 patients with $\mathrm{G} 2$ and 2 patients with G3. Comparing both groups, no statistically significant difference was noted (Table II).

In both examined groups, 2 cases were cervical adenocarcinoma and other cases involved cervical squamous cell carcinoma. The distribution of cancer histological types in both examined groups did not indicate any statistically significant differences (Table II).

An average number of lymph nodes in the group of patients who underwent classical surgery was 15.7 \pm 7.6 ), while in the group of patients operated with the nerve-sparing technique $-25.4( \pm 9.6)$ and this difference was statistically significant $(p<0.0001)$ (Table II).

The average time of nerve-sparing surgery amounted to 149 minutes ( \pm 46 minutes), while the average time of the classical radical hysterectomy was $141 \mathrm{~min}$ utes ( \pm 27 minutes) and did not differ statistically.

In every examined group, 5 cases of metastases to lymph nodes were noted. The infiltration in parametria was observed in 5 patients operated in the classical manner and in 2 patients operated with the use of the technique which saved vegetative innervation. In both groups, no statistically significant differences were stated (Table II). Cancer in the incision line was noted in 6 cases operated in the classical manner. It was not observed in the cases operated with the use of the nerve-sparing technique. Embolisms with cancer cells in the vessels were observed in 5 patients operated in the classical manner and 1 patient operated with the use of the nerve-sparing technique, respectively. In both groups, no other metastases were observed (Table II).

Patients who underwent nerve-sparing surgery were discharged from the hospital 7.5 days after the surgery $( \pm 5.7)$, while patients after classic surgeries on the $9^{\text {th }}$ day $( \pm 3.1)(p=0.062)$.

Tab. I. Clinical data of the patients

\begin{tabular}{lccc}
\hline & $\begin{array}{c}\text { Classical radical hysterectomy } \\
n=53(72 \%)\end{array}$ & Nerve-sparing radical hysterectomy \\
$n=20(28 \%)$ & $p$ \\
\hline Age (median, range) & $52(30-78)$ & $56(36-75)$ & NS \\
\hline Stage by FIGO: & & & \\
\hline IA2 & $19(36 \%)$ & $4(20 \%)$ & NS \\
\hline IB1 & $22(41.5 \%)$ & $12(60 \%)$ & $3(15 \%)$ \\
\hline IB2 & $4(7.5 \%)$ & $1(5 \%)$ & \\
\hline IA1 & $8(15 \%)$ & & \\
\hline
\end{tabular}

Tab. II. Histopathological analysis

\begin{tabular}{|c|c|c|c|}
\hline & $\begin{array}{l}\text { Classical radical hysterectomy } \\
\qquad n=53(72 \%)\end{array}$ & $\begin{array}{l}\text { Nerve-sparing radical hysterectomy } \\
\qquad n=20(28 \%)\end{array}$ & $p$ \\
\hline \multicolumn{3}{|l|}{ Histology: } & \multirow{3}{*}{ NS } \\
\hline Squamous cell carcinoma & $51(96 \%)$ & $18(90 \%)$ & \\
\hline Adenocarcinoma & $2(4 \%)$ & $2(10 \%)$ & \\
\hline \multicolumn{3}{|l|}{ Grade of cancer: } & \multirow{4}{*}{ NS } \\
\hline G1 & $15(28 \%)$ & $6(30 \%)$ & \\
\hline G2 & $32(60 \%)$ & $11(55 \%)$ & \\
\hline G3 & $7(12 \%)$ & $3(15 \%)$ & \\
\hline \multicolumn{4}{|l|}{ Number of lymph nodes } \\
\hline Mean \pm SD & $15.7( \pm 7.6)$ & $25.4( \pm 9.6)$ & $p<0.0001$ \\
\hline Metastases to lymph nodes & $5(9.4 \%)$ & $5(25 \%)$ & NS \\
\hline Infiltration in parametria & $5(9.4 \%)$ & $2(10 \%)$ & NS \\
\hline Cancer in the incision line & $6(11.3 \%)$ & 0 & \\
\hline Embolisms with cancer cells in the vessels & $5(9.4 \%)$ & $1(5 \%)$ & NS \\
\hline
\end{tabular}


Tab. III. Surgical complications

\begin{tabular}{lccc}
\hline & $\begin{array}{c}\text { Classical radical hysterectomy } \\
n=53(72 \%)\end{array}$ & $\begin{array}{c}\text { Nerve-sparing radical hysterectomy } \\
n=20(28 \%)\end{array}$ & $p$ \\
\hline Mid-surgical complications & $4(7.5 \%)$ & 0 & NS \\
\hline $\begin{array}{l}\text { Post-surgical decrease in hemoglobin } \\
\text { concentration [g\%] mean } \pm \text { SD }\end{array}$ & $3.1( \pm 1.5)$ & $2.4( \pm 1.1)$ & NS \\
\hline $\begin{array}{l}\text { Red blood cells concentrate transfusion } \\
\text { Early post-surgical complications }\end{array}$ & $14(26.4 \%)$ & $1(5 \%)$ & NS \\
\hline $\begin{array}{l}\text { Hospital stay [days] } \\
\text { mean } \pm \text { SD }\end{array}$ & $15(28.3 \%)$ & $1(5 \%)$ & NS \\
\hline Post-surgical complications (other) & $9.2( \pm 3.05)$ & $7.5( \pm 5.7)$ & - \\
\hline
\end{tabular}

Mid-surgical complications were observed in 4 (7.5\%) patients operated in the classic manner. They involved: 2 cases of urinary bladder damage, 1 case of ureter damage and 1 case of intensified bleeding. In the group of patients operated with the use of the method which saved vegetative innervation, no mid-surgical complications were noted. Average post-surgical decrease in hemoglobin concentration amounted to $3.1 \pm 1.5 \mathrm{~g} \%$ in the group operated in the classic manner and 2.4 $\pm 1.1 \mathrm{~g} \%$ in the group operated with the use of the nerve-sparing technique, respectively, and did not differ significantly. In the case of classic surgeries, there were at least 2 units of red blood cells concentrate transfused in 14 (26.4\%) patients, while in the group which underwent nerve-sparing surgery it took place in $1(5 \%)$ patient $(p=0.0901)$. Early post-surgical complications were observed in 15 (28.3\%) patients after classic surgery. In 13 of them, it was an infectious complication defined by body temperature rise above $38^{\circ} \mathrm{C}$, which remained for over 48 hours. In 1 case, carotid artery thrombosis was diagnosed and in 1 case vaginal bleeding occurred that required surgical intervention. In the group of patients operated with the use of the nerve-sparing technique, 1 case of fever was noted. In two patients who underwent classic surgery the vesicovaginal fistulas were observed (Table III).

\section{Discussion}

The evaluation of effectiveness and efficacy of radical hysterectomy which saves vegetative innervation in the world literature is limited only to assessment of urinary bladder function with a special attention paid to returning to unassisted micturition and the volume of retained urine. Unfortunately, the assessments were not standardized. Various techniques of radical hysterectomy, which saves vegetative innervation were applied, the patients underwent various post-surgical treatment (e.g. the time of maintaining the Foley catheter amounted from 3 to 9 days, catheterization was applied for various periods, suprapubic catheter was applied). Hockel et al. [17] stated that in all patients who underwent radical hysterectomy, which saved vegetative innervation even on the $12^{\text {th }}$ day urine retention amounted to less than $50 \mathrm{ml}$. In the urodynamic testing of the patients after classic radical hysterectomy, Sasaki et al. [18] observed decrease in the maximum urethral closure pressure. The authors think that it is caused by the damage of the hypogastric nerve, which goes in the uterosacral ligament. Pieterse et al. [19] after 24-month observation of 94 patients after radical hysterectomy, noted more frequent sexual disorders in the form of poor vaginal lubrication, vagina narrowing and shortening, vulvar paresthesia, dyspareunia and lack of sexual satisfaction. While Maas et al. [20] stated that patients after hysterectomy of the nerve-sparing type did not differ in terms of sexual satisfaction from healthy patients.

In our work we are focusing mostly on the assessment of the course, oncological radicalness and complications of the radical hysterectomy procedure with the use of the classic technique as well as with the use of the nerve-sparing technique.

In both groups which were subject to comparison, cervical squamous cell carcinoma was dominant and the age of patients was similar. Among the patients who underwent the nerve-sparing procedure, most $(60 \%)$ were diagnosed with IB1 clinical progression level. We did not state any statistically significant differences as far as the number of metastases in lymph nodes determined post surgery is concerned as well as the presence of cancer infiltration within the surgical line and presence of embolisms from cancer cells within the vessels. Similar conclusions were drawn in the meta-analysis of Cochrane data base, which covered 9 clinically controlled trials which compared classic radical hysterectomies and nerve-sparing surgeries (742 patients in total). No statistically significant differences were stated between the groups in terms of the post-surgical survival rate as well as the number of recurrences of malignant disease. Also no statistical differences were noted as far as the amount of surgical 
blood loss is concerned as well as the surgery oncological extension [21].

In our retrospective study, during the nerve-sparing surgeries a statistically significant higher number of lymph nodes excised was obtained. The average number of lymph nodes in the group of patients who underwent classic surgery amounted to 15.7, while in the other group operated with the use of the nerve-sparing technique - 25.4. It has to be underlined that requirements concerning the surgical technique in the case of radical hysterectomy, which saves vegetative innervation are much higher than in the case of classic radical hysterectomy. It concerns mostly detailed knowledge on the anatomy structures harvested and excised during the surgery. Therefore, the learning curve for nervesparing surgeries is longer in comparison to classic hysterectomy and only the most experienced surgeons carry out the procedures. It has to be noted that this type of surgeries have been done in our department since 2010. It allowed improving the surgical technique and obtaining, inter alia, a higher average number of lymph nodes harvested. It does not seem that the application of nerve-sparing surgery assures an increase in the number of excised lymph nodes during the surgery. It is rather connected with the qualification improvement and experience gained by surgeons.

In our own material, no statistically significant differences were observed with reference to the number of mid- and post-surgical complications. Average hospitalization time was similar as well as the frequency of red blood cells concentrate transfusion. Ju et al. [22] compared the groups of patients with cervical cancer operated with the use of the classic and nerve-sparing technique. The first group was composed of 69 patients while the group operated with the use of the method, which saved vegetative innervation consisted of 24 patients. Similarly to our group, the average surgery time was not statistically different and amounted for both groups to 147 vs. 143 minutes, respectively (ns), hospitalization time amounted for both groups to 10.2 vs. 10.2 days, respectively (ns) and did not statistically differ. In both groups, no cancerous infiltrations in the surgical incision line were stated. During the 6-month post-surgical observation, the authors noted greater satisfaction from sexual life in patients after surgery, which saved vegetative innervation. Similar conclusions were drawn by Espino-Strebel et al. [23] who performed nervesparing surgery and classical radical hysterectomy in 121 patients. They did not observe any essential differences during the surgery, blood loss, hospitalization or mortality.

Radical hysterectomy, which saves vegetative innervation or the primary radiotherapy seems to be the first-line treatment in early stages of cervical caner. On the grounds of own observations and based on the aforementioned data from the world literature, we can state that nerve-sparing surgery does not in- crease the operative time and does not cause greater blood loss. Its application has no negative impact on the oncological radicality of the procedure. When comparing the results of classical radical hysterectomy with the nerve-sparing technique, one can state that there are no essential differences in the number of mid- and post-surgical complications $[24,25]$. The sparing procedure provides, what is confirmed by the results from Cochrane data base, essential benefits related to the functioning of urinary bladder, post-surgical return of intestines function and general improvement of the quality of life of patients treated for cervical cancer. A conclusion may be drawn that nerve-sparing surgery, despite its preservative character, should not worsen the prognosis of patients and is an alternative method to classical procedures. However, it has to be marked that observations of oncological efficiency of the surgery are limited and require longer follow-up.

\section{Disclosure}

Authors report no conflicts of interest.

\section{References}

1. Krajowy Rejestr Nowotworów. Centrum Onkologii - Instytut im. Marii Skłodowskiej-Curie. Zakład Epidemiologii i Prewencji Nowotworów; http://epoid.coi.waw.pl/krn

2. Michalska M. Epidemiologia raka szyjki macicy. In: Rak szyjki macicy. Profilaktyka, diagnostyka i leczenie. Spaczyński M, Kędzia W, Nowak-Markwitz E (eds.). Wydawnictwo Lekarskie PZWL, Warszawa 2009.

3. Skręt A, Nowakowski B, Skręt-Magierło J, et al. Radykalna histerektomia oszczędzająca unerwienie wegetatywne. Ginekol Pol 2008; 79: 92-98.

4. Sakamoto S, Takaziwa K. An improved radical hysterectomy with fewer urological complications with no loss of therapeutic results for invasive cervical cancer. Ballieres Clin Obstet Gynaecol 1988; 2: 953-962.

5. Querleu D, Morrow CP. Classification of radical hysterectomy. Review. Lancet Oncol 2008; 9: 297-303.

6. Kato T, Murakami G, Yabuki Y. Does the cardinal ligament of the uterus contain a nerve that should be preserved in radical hysterectomy? Anat Sci Int 2002; 77: 161-168.

7. Niikura $\mathrm{H}$, Katahira $\mathrm{A}$, Utsunomiya $\mathrm{H}$, et al. Surgical anatomy of intrapelvic fasciae and vesico-uterine ligament in nerve-sparing radical hysterectomy with fresh cadaver dissections. Tohoku J Exp Med 2007; 212: 403-413.

8. Maas C, Kenter G, Trimbos J, et al. Anatomical basis for nerve-sparing radical hysterectomy: immunohistochemical study of the pelvic autonomic nerves. Acta Obstet Gynecol Scand 2005; 84: 868-874.

9. Raspagliesi F, Ditto A, Kusamura S, et al. Nerve-sparing radical hysterectomy: a pilot study. Tumori 2003; 89: 497-501.

10. Sakuragi N, Todo Y, Kudo M, et al. A systematic nerve-sparing radical hysterectomy technique in invasive cervical cancer for preserving postsurgical bladder function. Int I Gynecol Cancer 2005; 15: 389-397.

11. Fujii S, Takakura K, Matsumura N, et al. Precise anatomy of the vesicouterine ligament for radical hysterectomy. Gynecol Oncol 2007; 104: 186-191.

12. Maas C, Trimbos J, DeRuiter M, et al. Nerve sparing radical hysterectomy: latest developments and historical perspective. Crit Rev Oncol Hematol 2003; 48: 271-279.

13. Kobayashi T. Abdominal radical hysterectomy with pelvic lymphadenectomy for cancer of cervix. $2^{\text {nd }}$ ed. Nanzando, Tokyo 1961; 178-187.

14. Okabayashi H. Radical abdominal hysterectomy for cancer of the cervix uteri, modification of the takayama operation. Surg Gynecol Obstet 1921; 33: 335-341. 
15. Yabuki Y, Asamoto A, Hoshiba T, et al. Radical hysterectomy: An anatomic evaluation of parametrial dissection. Gynecol Oncol 2000; 77 155-163.

16. Piver MS, Rutledge F, Smith J. Five classes of extended hysterectomy for women with cervical cancer. Obstet Gynecol 1974; 44: 265-272.

17. Hockel M, Konerding M, Heussel C. Liposuction-assisted nerve-sparing extended radical hysterectomy: oncologic rationale, surgical anatomy, and feasibility study. Am J Obstet Gynecol 1998; 178: 971-976.

18. Sasaki H, Yoshida T, Noda K, et al. Urethral pressure profiles following radical hysterectomy. Obstet Gynecol 1982; 59: 101-104.

19. Pieterse $\mathrm{Q}$, Maas C, ter Kuile $\mathrm{M}$, et al. An observational longitudinal study to evaluate miction, defecation, and sexual function after radical hysterectomy with pelvic lymphadenectomy for early-stage cervical cancer. Int J Gynecol Cancer 2006; 16: 1119-1129.

20. Maas C, ter Kuile M, Laan E, et al. Objective assessment of sexual arous al in woman with a history of hysterectomy. BJOG 2004; 111: 456-462.
21. Long Y, Yao DS, Zhou KC. Clinical effect of nerve sparing radical hysterectomy for cervical cancer: a systematic review. Chinese Journal of Evidence-Based Medicine 2010; 10: 1205-1212

22. Ju XZ, Li ZT, Yang HJ, et al. Nerve-sparing radical hysterectomy and radical hysterectomy: a retrospective study. Zhonghua Fu Chan Ke Za Zhi 2009; 44: 605-609.

23. Espino-Strebel EE, Luna JT, Domingo EJ. A comparison of the feasibility and safety of nerve-sparing radical hysterectomy with the conventional radical hysterectomy. Int J Gynecol Cancer 2010; 20: 1274-1283.

24. Ebert A, Ulrich U, Beckmann M, et al. Unanswered questions in the management of cervical cancer. Zentralbl Gynakol 2006; 128: 23-26.

25. Kuwabara Y, Suzuki M, Hashimoto $M$, et al. New method to prevent bladder dysfunction after radical hysterectomy for uterine cervical cancer. J Obstet Gynaecol Res 2000; 26: 1-8. 